\title{
Nutritional deficiencies and predictors of mortality in diabetic and nondiabetic gastroparesis
}

\author{
Waseem Amjada, Waqas Qureshib, Ritu R. Singh ${ }^{c, d}$, Seth Richter
}

Albany Medical Center, NY; University of Massachusetts, Worchester, MA; Indiana University School of Medicine, Fort Wayne; John Hopkins Bloomberg School of Public Health, USA

\section{Abstract}

\section{Introduction}

Gastroparesis is a complex, debilitating syndrome with symptoms that include nausea, vomiting, and postprandial

\begin{abstract}
aDepartment of Internal Medicine, Albany Medical Center, Albany, NY (Waseem Amjad); ${ }^{b}$ Department of Cardiovascular Medicine, University of Massachusetts, Worchester, MA (Waqas Qureshi); ${ }^{\mathrm{c}}$ Department of Medicine, Indiana University School of Medicine, Fort Wayne, Indiana, USA (Ritu R. Singh); 'Johns Hopkins Bloomberg School of Public Health (Ritu R. Singh); 'Department of Gastroenterology, Albany Medical Center, Albany NY (Seth Richter), USA

Conflict of Interest: None
\end{abstract}

Correspondence to: Waseem Amjad, MD, Department of Internal Medicine, Albany Medical Center, 178 Washington Ave Ext, Albany NY 12203, USA, e-mail: waseemonline001@gmail.com

Received 17 March 2021; accepted 16 June 2021; published online 14 September 2021

DOI: https://doi.org/10.20524/aog.2021.0660 abdominal pain or fullness [1]. The Olmstead community study showed estimates of almost $2 \%$, higher than the national prevalence. Gastroparesis is underdiagnosed, as the gastric emptying test is not commonly performed, and the patients identified are the tip of the iceberg [2]. It afflicts $5.2 \%$ of type 1 diabetics, $1 \%$ of type 2 diabetics, and $0.2 \%$ of individuals without diabetes mellitus (DM) [3]. It is more common in women than men. The prevalence of diabetic gastroparesis is expected to rise with the increasing prevalence of DM.

The poor oral intake in severe cases of gastroparesis can lead to malnutrition [4]. Micronutrient deficiencies are commonly observed in this population and may contribute to the disease burden [5]. Because of their poor nutrition, these patients require frequent hospitalizations secondary to gastroparesis, which impose a major burden on the health care system [6,7].

Long-term studies examining the impact of gastroparesis on morbidity and mortality are lacking. To date, the few epidemiological studies have shown heterogeneous results in terms of mortality [8-10]. The data regarding populations at risk of high mortality are deficient. Therefore, it is prudent to examine 
the risk factors and predictors of adverse outcomes in patients with gastroparesis. The literature shows that gastroparesis patients consume food deficient in essential nutrients $[5,11]$. The effect of poor nutrition on the clinical outcomes is not well documented. Therefore, we aimed to study the predictors of mortality in diabetic and nondiabetic gastroparesis, and to estimate the prevalence of clinical malnutrition and micronutrient deficiencies among these patients.

\section{Patients and methods}

\section{Study population}

This retrospective cohort study was conducted at a tertiary care hospital in Albany, located in upstate New York, which has a large catchment area. After the chart review, we identified all patients diagnosed with gastroparesis between Sept 30, 2009 and January 31,2020 . The follow up was $100 \%$ in our patients because they were followed by the same gastroparesis clinic. The study was approved by the institutional review board of Albany Medical Center, with patient consent waived.

The hospital record was reviewed, and the patients labeled with gastroparesis and had a delayed gastric emptying study were identified. We included patients older than 18 years diagnosed with gastroparesis on the solid and/or liquid gastric emptying study (outpatient and inpatient). Patients were excluded if they were older than 90 years. The cases with incomplete gastric emptying scintigraphy $(n=15)$, evidence of mechanical gastric outlet obstruction $(n=6)$, peptic ulcer disease $(n=17)$, and those with clinically diagnosed gastroparesis with a normal gastric emptying study $(n=518)$ were excluded. The date of the first gastric emptying study was considered as the baseline date.

\section{Baseline data and covariates}

Gastroparesis was defined as delayed gastric emptying of solids and liquids on a scintigraphic gastric emptying study. ${ }^{99 \mathrm{~m} T c}$ sulfur colloid-labeled liquid and solid foods were used as test meals. Gastric retention of $\geq 10 \%$ of solids at $4 \mathrm{~h}$ and $\geq 5 \%$ of liquids at $1 \mathrm{~h}$ were identified as delayed gastric emptying. The definition of delayed gastric emptying of liquids at $60 \mathrm{~min}$ was based on the institutional nuclear radiology consensus. In a few cases when tests were performed for both solids and liquids, the date of the first test was recorded. The cases with isolated delayed gastric emptying with liquids were also considered as gastroparesis. Severe gastroparesis was defined as gastric retention of $>35 \%$ of the test meal after $4 \mathrm{~h}$ for solids and $1 \mathrm{~h}$ for liquids [12]. Per institutional policy, opiates were stopped at least $24-48 \mathrm{~h}$ before the study.

Vitamin D deficiency was defined as 25-OH-vitamin D3 levels less than $30 \mathrm{ng} / \mathrm{mL}$. Vitamin B12 deficiency was defined as levels below $300 \mathrm{ng} / \mathrm{mL}$. Patients diagnosed with vitamin deficiencies and received supplements (inaccessible labs) were also included. Iron deficiency was diagnosed if ferritin levels were less than $30 \mathrm{ng} / \mathrm{mL}$.
In patients with indeterminate range ferritin $(30-100 \mathrm{ng} / \mathrm{mL})$, iron deficiency anemia was differentiated from anemia of chronic disease with low serum iron, low serum transferrin saturation and normal or high total iron binding capacity [13].

DM was defined based on one of the following criteria before the diagnosis of gastroparesis: a) International Classification of Diseases ICD-9 and ICD-10 codes and treated with insulin or oral hypoglycemics for at least 30 days; b) glucose levels $\geq 200 \mathrm{mg} / \mathrm{dL}$ on 2 separate occasions; c) glucose $\geq 200 \mathrm{mg} / \mathrm{dL}$ at least once and treated with oral hypoglycemics or insulin for at least 30 days) glucose levels above $126 \mathrm{mg} / \mathrm{dL}$ on least 2 separate occasions and treated for at least 30 days [14]. Chronic kidney disease (CKD) was defined as GFR $<60 \mathrm{~mL} / \mathrm{min} / 1.73 \mathrm{~m}^{2}$ measured on 2 separate occasions [15]. Malnutrition was defined as a lack of intake of essential nutrients, leading to altered body composition, poor clinical outcomes and decreased physical function. Although individuals with overnutrition can also suffer from malnutrition, our study only labeled patients with undernutrition as malnourished. In accordance with the guidelines of the American Society for Parenteral and Enteral Nutrition, these patients were identified objectively by 2 of the following criteria: reduced weight, muscle wasting, loss of subcutaneous fat, fluid accumulation and decreased hand grip [16,17]. Patients with body mass index (BMI) $\geq 30 \mathrm{~kg} / \mathrm{m}^{2}$ were classified as obese. Biochemical values, including hemoglobin, liver function test, glycated hemoglobin A1c, serum creatinine, albumin, calcium, vitamin B12 and D levels, were extracted from the routine laboratory data, taking the mean of the 2 most recent values before the baseline. Type 1 and $2 \mathrm{DM}$ were not differentiated. Injectable medications such as glucagon-like peptide-1 agonists were recorded as non-insulin injectables.

Baseline demographic data, including age, sex, race, and comorbidities such as obesity, hypertension, gastroesophageal reflux disease (GERD), coronary artery disease (CAD), chronic obstructive pulmonary disease (COPD), history of cancer, and autoimmune disorder, were extracted after careful chart review. Medication use, including proton-pump inhibitor, $\mathrm{H}_{2}$-receptor blocker, opiates, antidepressants, prokinetics, oral hypoglycemics, insulin, vitamin supplements and benzodiazepines, were recorded from the medication history at the time of diagnosis or from the most recent prescription record before the gastric emptying study.

During the study period 320 patients were included in the study. The study subjects were segregated into diabetics and nondiabetics.

\section{Outcomes}

Our primary outcome was all-cause mortality in diabetics and nondiabetics. Patients were censored when mortality occurred or when the last day of follow up was achieved, whichever came earlier. We also aimed to determine the predictors of mortality among diabetics and nondiabetics. The secondary outcome was the prevalence of clinical malnutrition, vitamin $\mathrm{D}$, vitamin $\mathrm{B} 12$, and iron deficiencies. 


\section{Statistical analysis}

The baseline characteristics were presented as percentages for the categorical variables and means $\pm S D$ for continuous variables, and were compared between diabetic and nondiabetic gastroparesis patients. A multivariate logistic regression model was used to assess the association of diabetes and other covariates with mortality during the study period. These models were adjusted for age, sex, race, obesity, BMI, hypertension, diabetes, GERD, CKD, CAD, obesity, COPD, autoimmune disease, cancer, neuromuscular disease, use of proton-pump inhibitor, use of $\mathrm{H}_{2}$-receptor blocker, use of opioids, use of antidepressants, use of prokinetic, use of oral or injectable non-insulin drugs, use of insulin, and vitamin D and B12 deficiencies. We also evaluated the same predictors among the diabetic and nondiabetic subgroups. To keep the multivariate model brief, we performed backward stepwise regression and only variables with an association of $\mathrm{P}<0.05$ were included in the model. We also compared levels of calcium, vitamin D, vitamin B12, albumin and folate between diabetics and nondiabetics, using a $t$-test or Mann-Whitney $U$ test if the distribution was skewed. All analysis was conducted using statistical software PASW v. 18 (SPSS Inc., Chicago, IL). A P-value $<0.05$ was considered significant.

\section{Results}

\section{Demographics}

During the study period 1148 patients had a gastric emptying study with suspicion of gastroparesis. Of these patients, 272 were either younger than 18 years or older than 90 . Among the reviewed charts 38 patients were excluded because of an incomplete study, endoscopic diagnosis of mechanical obstruction, gastric cancer, or peptic ulcer disease. A negative gastric emptying study was observed in 518 patients. Thus, a total of 320 patients were included in the analysis (Fig. 1), of whom 127 (39.7\%) had DM and 193 (60.3\%) did not.

The patients' mean age was $47.5 \pm 5.3$ and $70 \%$ were female. The major secondary diagnoses were obesity $(42.8 \%)$, hypertension (39.7\%), GERD (63.8\%), CKD (18.8\%), CAD (15.3\%), COPD (13.4\%), autoimmune disease (10.3\%), neuromuscular disease (5.9\%), cancers (10\%), clinical malnutrition (20\%), and history of gastric bypass (8.1\%). Of 204 patients with GERD, 17.1\% had esophagitis on endoscopy. This was observed in $20 \%$ of the GERD patients with DM and $15.4 \%$ of the nondiabetics $(\mathrm{P}=0.4)$.

At the time of the diagnosis, a proton-pump inhibitor (80.3\%) was the most commonly prescribed medication in both groups, followed by antidepressants (60.6\%), opiates (41.6\%), $\mathrm{H}_{2}$-receptor blockers (23.7\%), and prokinetics (17.5\%). The prokinetic used prior to diagnosis was metoclopramide in 49 patients ( $15 \%$ in DM and $10 \%$ in nondiabetics), erythromycin in 3 patients, and combined metoclopramide and erythromycin in 7 patients.

The DM population was older $(51.0 \pm 15.0$ vs. $45.3 \pm 16.9$ years, $\mathrm{P}=0.002$ ) while the non-DM population had a more female $(76.2 \%$ vs. $60.6 \%, \mathrm{P}=0.003)$ and Caucasian (76.7\% vs. $63 \%, \mathrm{P}=0.008)$ population. Obesity ( $54.3 \%$ vs. $35.2 \%, \mathrm{P}=0.001)$, hypertension $(63.0 \%$ vs. $24.4 \%, \mathrm{P}<0.001)$, CKD (35.4\% vs. $7.8 \%, \mathrm{P}<0.001)$ and CAD $(29.1 \%$ vs. $6.2 \%$, $\mathrm{P}<0.001)$ were more common in the diabetic population, whereas GERD ( $68.9 \%$ vs. $55.9 \%, \mathrm{P}=0.02$ ) was more common in nondiabetics. The DM gastroparesis patients had lower hemoglobin levels and higher white blood cell counts, serum creatinine and alkaline phosphate levels (Table 1). The median duration of DM at the time of the diagnosis of gastroparesis was 10 years (interquartile range 4-18). DMrelated complications were seen in 66 patients (52\%): these included $15 \%$ retinopathy, $18.9 \%$ nephropathy, and $36.2 \%$ neuropathy.

A total of $42(13.1 \%)$ patients had a history of bariatric or esophageal surgery (26 bariatric surgery and 18 esophageal surgery). Post-surgical gastroparesis was more common in nondiabetics $8(6.3 \%)$ vs. 35 (18.1\%), $\mathrm{P}=0.002$. The causes

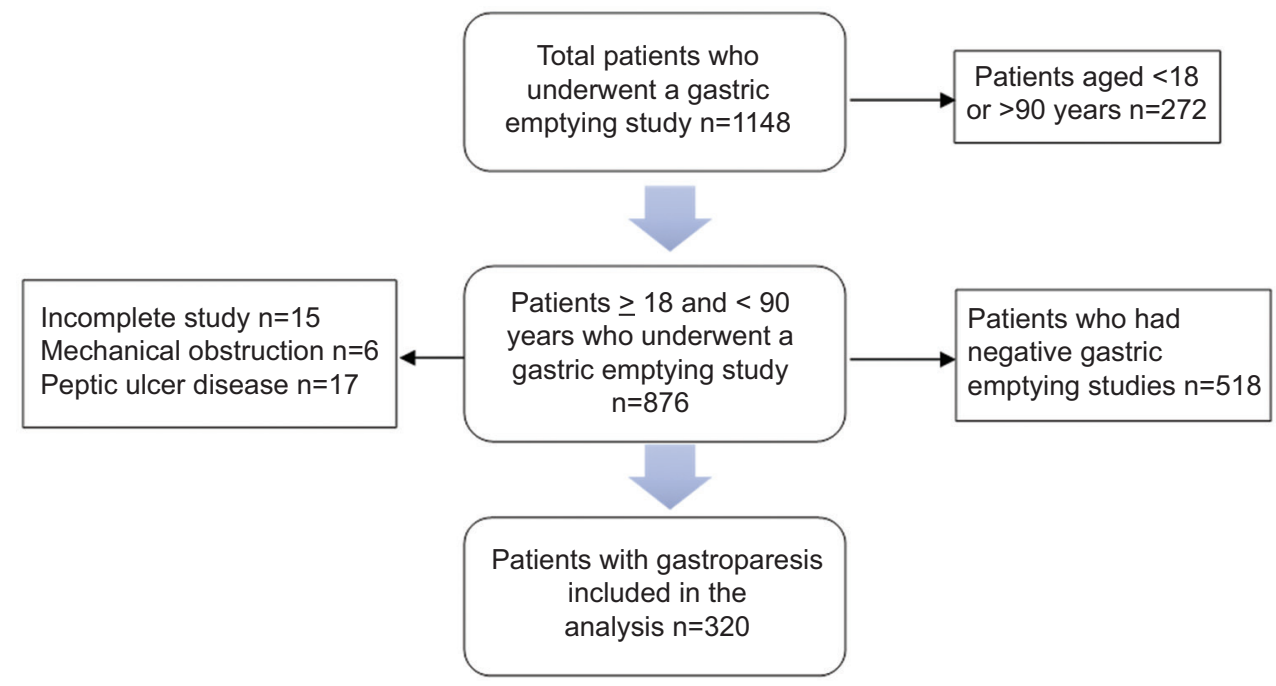

Figure 1 Flowchart showing gastroparesis patient population 
Table 1 Patients' characteristic and comparison of diabetic gastroparesis with nondiabetic gastroparesis

\begin{tabular}{|c|c|c|c|c|}
\hline Variables & Total cases & $\begin{array}{l}\text { Diabetic gastroparesis } \\
\qquad \mathrm{N}=127\end{array}$ & $\begin{array}{l}\text { Nondiabetic gastroparesis } \\
\qquad \mathrm{N}=193\end{array}$ & $\begin{array}{c}\text { Two-group comparison } \\
\text { (P-value) }\end{array}$ \\
\hline $\begin{array}{l}\text { Demographics } \\
\text { Age (mean } \pm \text { SD) } \\
\text { Females } \\
\text { Whites }\end{array}$ & $\begin{array}{c}47.5 \pm 5.3 \\
224(70 \%) \\
228(71.3 \%)\end{array}$ & $\begin{array}{c}51.0 \pm 15.0 \\
77(60.6 \%) \\
80(63.0 \%)\end{array}$ & $\begin{array}{c}45.3 \pm 16.9 \\
147(76.2 \%) \\
148(76.7 \%)\end{array}$ & $\begin{array}{l}0.002 \\
0.003 \\
0.008\end{array}$ \\
\hline $\begin{array}{l}\text { Comorbid conditions } \\
\text { BMI, } \mathrm{kg} / \mathrm{m}^{2}(\text { mean } \pm \mathrm{SD}) \\
\text { Obesity } \\
\text { Hypertension } \\
\text { GERD } \\
\text { CKD } \\
\text { CAD } \\
\text { COPD } \\
\text { Gastric bypass } \\
\text { Esophageal surgery } \\
\text { Autoimmune } \\
\text { Cancer } \\
\text { Neuromuscular disease }\end{array}$ & $\begin{array}{c}29.2 \pm 8.8 \\
137(42.8 \%) \\
127(39.7 \%) \\
204(63.8 \%) \\
60(18.8 \%) \\
49(15.3 \%) \\
43(13.4 \%) \\
26(8.1 \%) \\
18(5.6 \%) \\
33(10.3 \%) \\
32(10 \%) \\
19(5.9 \%)\end{array}$ & $\begin{array}{c}31.6 \pm 8.7 \\
69(54.3 \%) \\
80(63.0 \%) \\
71(55.9 \%) \\
45(35.4 \%) \\
37(29.1 \%) \\
14(11.0 \%) \\
7(5.5 \%) \\
2(1.2 \%) \\
13(10.2 \%) \\
15(11.8 \%) \\
8(6.3 \%)\end{array}$ & $\begin{array}{c}27.7 \pm 8.3 \\
68(35.2 \%) \\
47(24.4 \%) \\
133(68.9 \%) \\
15(7.8 \%) \\
12(6.2 \%) \\
29(15.0 \%) \\
19(9.8 \%) \\
16(8.3 \%) \\
20(10.4 \%) \\
17(8.8 \%) \\
11(5.7 \%)\end{array}$ & $\begin{array}{c}<0.001 \\
0.001 \\
<0.001 \\
0.02 \\
<0.001 \\
<0.001 \\
0.30 \\
0.21 \\
0.004 \\
0.97 \\
0.15 \\
0.81\end{array}$ \\
\hline $\begin{array}{l}\text { Nutritional deficiencies } \\
\text { Clinical malnutrition } \\
\text { Vitamin D deficiency } \\
\text { Vitamin B12 deficiency } \\
\text { Iron deficiency } \\
\text { Nutrition evaluation }\end{array}$ & $\begin{array}{c}64(20 \%) \\
159(49.7 \%) \\
56(17.5 \%) \\
161(50.3 \%) \\
62(19.4 \%)\end{array}$ & $\begin{array}{l}29(22.8 \%) \\
68(53.5 \%) \\
16(12.6 \%) \\
70(55.1 \%) \\
29(22.8 \%)\end{array}$ & $\begin{array}{l}35(18.1 \%) \\
91(47.3 \%) \\
40(20.7 \% \\
91(47.2 \%) \\
33(17.1 \%)\end{array}$ & $\begin{array}{l}0.39 \\
0.26 \\
0.06 \\
0.17 \\
0.18\end{array}$ \\
\hline 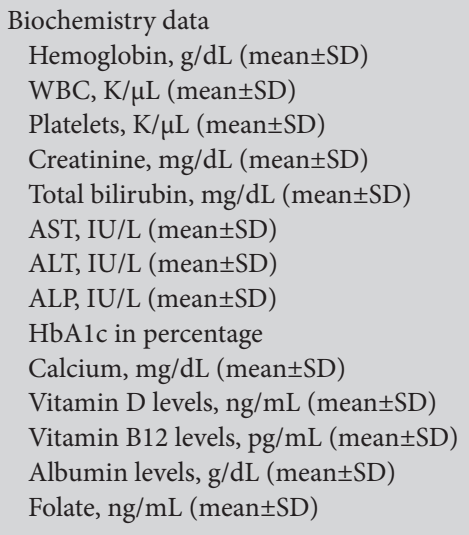 & $\begin{array}{c}12.0 \pm 2.0 \\
7.8 \pm 2.8 \\
269.4 \pm 92.2 \\
1.2 \pm 1.6 \\
0.7 \pm 0.8 \\
26.0 \pm 28.6 \\
25.1 \pm 23.6 \\
85.7 \pm 69.4 \\
7.3 \pm 2.4 \\
9.0 \pm 0.6 \\
22.6 \pm 10.7 \\
456.6 \pm 214.7 \\
3.6 \pm 0.7 \\
13.6 \pm 6.4\end{array}$ & $\begin{array}{c}11.7 \pm 2.1 \\
8.4 \pm 3.1 \\
265.5 \pm 90.9 \\
1.6 \pm 2.3 \\
0.8 \pm 1.1 \\
28.4 \pm 36.1 \\
26.6 \pm 23.6 \\
98.6 \pm 101.2 \\
8.3 \pm 2.3 \\
9.0 \pm 0.7 \\
21.6 \pm 9.8 \\
446.8 \pm 186.1 \\
3.5 \pm 0.7 \\
12.4 \pm 5.2\end{array}$ & $\begin{array}{c}12.2 \pm 1.9 \\
7.4 \pm 2.6 \\
272.0 \pm 93.2 \\
0.85 \pm 0.61 \\
0.6 \pm 0.3 \\
24.2 \pm 22.0 \\
24.2 \pm 22.0 \\
76.7 \pm 29.8 \\
5.6 \pm 1.5 \\
9.0 \pm 0.5 \\
23.4 \pm 11.3 \\
462.7 \pm 231.6 \\
3.6 \pm 0.6 \\
14.2 \pm 7.0\end{array}$ & $\begin{array}{c}0.03 \\
0.002 \\
0.54 \\
<0.001 \\
0.06 \\
0.21 \\
0.37 \\
0.006 \\
<0.001 \\
0.91 \\
0.32 \\
0.67 \\
0.07 \\
0.20\end{array}$ \\
\hline $\begin{array}{l}\text { Medications } \\
\text { PPI } \\
\mathrm{H}_{2} \text {-receptor blocker } \\
\text { Opiates } \\
\text { Antidepressants } \\
\text { Prokinetics }\end{array}$ & $\begin{array}{c}257(80.3 \%) \\
76(23.7 \%) \\
133(41.6 \%) \\
194(60.6 \%) \\
56(17.5 \%)\end{array}$ & $\begin{array}{l}100(78.7 \%) \\
27(21.3 \%) \\
59(46.5 \%) \\
79(62.2 \%) \\
25(19.7 \%)\end{array}$ & $\begin{array}{c}157(81.3 \%) \\
49(25.4 \%) \\
74(38.3 \%) \\
115(59.6 \%) \\
31(16.1 \%)\end{array}$ & $\begin{array}{l}0.66 \\
0.40 \\
0.15 \\
0.64 \\
0.40\end{array}$ \\
\hline
\end{tabular}

Reference ranges: calcium 8.6-10.3 mg/dL; vitamin D 30-100 ng/mL; vitamin B12 300-900 pg/mL; albumin 4-5.2 gm/dL; folate 4-20 ng/mL

$S D$, standard deviation; GERD, gastroesophageal reflux disease; CAD, coronary artery disease; CKD, chronic kidney disease; COPD, chronic obstructive pulmonary disease; BMI, body mass index; WBC, white blood cell count; AST, aspartate transaminase; ALT, alanine transaminase; ALP, alkaline phosphatase; HbA1c, glycated hemoglobin; PPI, proton-pump inhibitor; H2, histamine receptor 2

of nondiabetic gastroparesis included a history of bariatric surgery $(9.8 \%)$, esophageal surgery $(8.3 \%)$, neuromuscular disease $(5.8 \%)$, infections $(4.6 \%)$, potential drug use (opiates $38.3 \%$, antidepressants $59.6 \%$ ), and idiopathic (35.5\%). A few patients had more than one of these causes.

The mean duration of follow up was $3.71 \pm 2.32$ years (3.44 \pm 2.31 years in DM and 3.9 \pm 2.31 years in nondiabetics).

\section{Mortality and clinical outcomes}

Of the 320 patients, 46 died during the study period, of whom 27 had DM and 19 did not have DM. When compared to nondiabetic gastroparesis, patients with diabetic gastroparesis had a higher cumulative incidence of death within the study period (Fig. 2). This is explained by the fact that the diabetic patients 
died earlier during the study period. However, multivariate analysis showed that there was no significant difference in mortality between the 2 groups $(\mathrm{P}=0.82)$. Heart disease was the most common cause of death in DM (33\%), followed by kidney disease and cancer (18.5\% each), whereas heart disease (26.3\%) and infections (26.3\%) were the most common causes of death in nondiabetics (Supplementary Table 1).

Patients with older age (hazard ratio [HR] 1.06, 95\% confidence interval [CI] 1.02-1.11; $\mathrm{P}=0.009)$, CKD (HR 12.94, 95\%CI 3.48-48.16; $\mathrm{P}<0.001$ ), CAD (HR 3.42, 95\%CI 1.03 11.3; $\mathrm{P}=0.04$ ), COPD (HR 3.32, 95\%CI 1.02-10.81; $\mathrm{P}=0.046$ ), and malnutrition (HR 5.63, 95\%CI 1.58-20.03; $\mathrm{P}=0.008$ ) had higher mortality. Deficiencies in vitamins B12 (HR 0.60, 95\%CI 0.09-3.86; $\mathrm{P}=0.38)$ and $\mathrm{D}$ (HR 1.62, 95\%CI 0.1418.92; $\mathrm{P}=0.7$ ), and iron deficiency anemia (HR 1.22, 95\%CI 0.34-4.39; $\mathrm{P}=0.76$ ) were not associated with higher mortality. Other comorbidities, including obesity, hypertension, GERD, autoimmune disorders, cancer, and history of gastroesophageal surgery, were not associated with higher mortality (Table 2).

A subgroup analysis was performed to determine the predictors of mortality in diabetics and nondiabetics (Table 3 ). Among diabetics, older age, CKD and malnutrition were associated with higher mortality, whereas nondiabetics with older age, $\mathrm{CKD}, \mathrm{CAD}, \mathrm{COPD}$, and malnutrition had higher mortality (Fig. 3A, B).

\section{Severe gastroparesis}

A total of 115 (35.9\%) patients had severe gastroparesis. DM was associated with a higher incidence of severe gastroparesis (47.2\% vs. $27.9 \%$, odds ratio $2.17,95 \%$ CI $1.23-3.83$; $\mathrm{P}=0.007$ ).

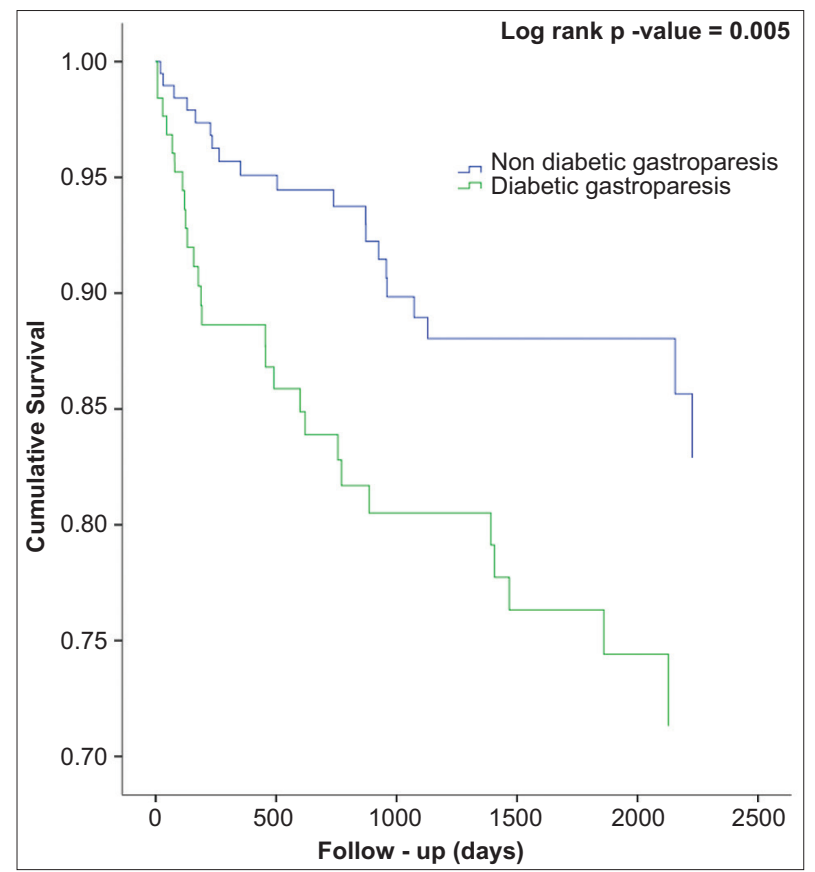

Figure 2 Cumulative incidence of survival by diagnosis (diabetic vs. nondiabetic gastroparesis)
Table 2 Predictors of outcome (multivariate model)

\begin{tabular}{|c|c|c|}
\hline Variable & $\begin{array}{c}\text { Hazard ratio } \\
\text { (95\% confidence } \\
\text { interval) }\end{array}$ & P-value \\
\hline Age & $1.06(1.02-1.11)$ & 0.009 \\
\hline Female & $1.26(0.42-3.79)$ & 0.69 \\
\hline Race & $0.55(1.13-2.25)$ & 0.41 \\
\hline Vitamin D deficiency & $1.62(0.14-18.92)$ & 0.7 \\
\hline Vitamin B12 deficiency & $0.60(0.09-3.86)$ & 0.38 \\
\hline Iron deficiency anemia & $1.22(0.34-4.39)$ & 0.76 \\
\hline Obesity & $2.21(0.17-3.8)$ & 0.46 \\
\hline BMI & $0.19(0.78-1.05)$ & 0.93 \\
\hline Hypertension & $0.22(0.06-0.79)$ & 0.02 \\
\hline Diabetes mellitus & $1.31(0.12-14.43)$ & 0.82 \\
\hline Malnutrition & $5.63(1.58-20.03)$ & 0.008 \\
\hline GERD & $1.4(0.38-5.18)$ & 0.61 \\
\hline Chronic kidney disease & $12.94(3.48-48.16)$ & $<0.001$ \\
\hline Coronary artery disease & $3.42(1.03-11.3)$ & 0.04 \\
\hline COPD & $3.32(1.02-10.81)$ & 0.046 \\
\hline Autoimmune & $0.65(0.12-3.42)$ & 0.61 \\
\hline Cancer & $1.43(0.32-6.32)$ & 0.64 \\
\hline Neuromuscular & $0.72(0.06-8.04)$ & 0.79 \\
\hline Proton-pump inhibitor & $1.68(0.3-9.33)$ & 0.55 \\
\hline $\mathrm{H}_{2}$-receptor blocker & $0.62(0.17-2.23)$ & 0.46 \\
\hline Opiate & $2.1(0.63-6.98)$ & 0.23 \\
\hline Antidepressants & $0.79(0.29-2.14)$ & 0.65 \\
\hline Prokinetic & $0.49(0.07-3.26)$ & 0.46 \\
\hline Oral and injectable non-insulin & $0.89(0.14-5.67)$ & 0.9 \\
\hline Insulin & $0.86(0.09-8.43)$ & 0.9 \\
\hline
\end{tabular}

BMI, body mass index; GERD, gastroesophageal reflux disease; COPD, chronic obstructive pulmonary disease; $\mathrm{H} 2$, histamine receptor 2

A gastrojejunostomy tube was required in $11.5 \%$ of the gastroparesis population $(6.3 \%$ in DM and $15.0 \%$ in non-DM, $\mathrm{P}=0.01$ ).

\section{Clinical recovery}

Clinical recovery was identified from the provider's documentation. At 12 weeks from baseline, 88 patients (27.4\%) patients had no clinical recovery. Of these, 28 (22.1\%) diabetics and $60(31.1 \%)$ nondiabetics had no recovery. These patients had higher mortality (HR 2.96, 95\% CI 1.6-5.47; P=0.001).

\section{Malnutrition and micronutrient deficiency}

Clinical malnutrition was observed in $22.8 \%$ patients with DM and $17.8 \%$ nondiabetics. Their BMI decreased 
Table 3 The predictors of mortality in diabetic and nondiabetic gastroparesis

\begin{tabular}{lcccc}
\hline Variables & Diabetic gastroparesis HR $(95 \% \mathrm{CI})$ & P-value & Nondiabetic gastroparesis HR (95\%CI) & P-value \\
\hline Age & $1.06(1.03-1.10)$ & $<0.001$ & $1.05(1.01-1.09)$ & .04 \\
Sex & $0.55(0.2-1.46)$ & 0.23 & $0.35(0.67-8.3)$ & .18 \\
Race & $0.75(0.35-1.59)$ & 0.45 & $2.49(0.63-9.85)$ & .79 \\
Iron deficiency & $1.31(0.45-3.78)$ & 0.62 & $0.30(0.06-1.62)$ & 0.19 \\
obesity & $2.45(0.78-7.74)$ & 0.13 & $0.37(0.09-1.53)$ & .16 \\
Hypertension & $0.63(0.21-1.92)$ & 0.42 & $10.2(2.48-41.99)$ & 0.17 \\
CKD & $4.69(1.62-13.59)$ & 0.004 & $9.7(1.8-52.21)$ & .001 \\
CAD & $2.44(0.98-6.05)$ & 0.05 & $7.5(2.11-26.82)$ & .008 \\
COPD & $0.42(0.08-2.21)$ & 0.31 & $2.9(0.67-12.44)$ & .002 \\
Cancer & $1.33(0.37-4.77)$ & 0.66 & $1.47(0.14-15.59)$ & .15 \\
Neuromuscular & & & $3.83(1.14-29.07)$ & .75 \\
Malnutrition & $10.95(3.23-37.17)$ & $<0.001$ & .03 \\
\hline
\end{tabular}

HR, hazard ratio; CI, confidence interval; CAD, coronary artery disease; CKD, chronic kidney disease; COPD, chronic obstructive pulmonary disease

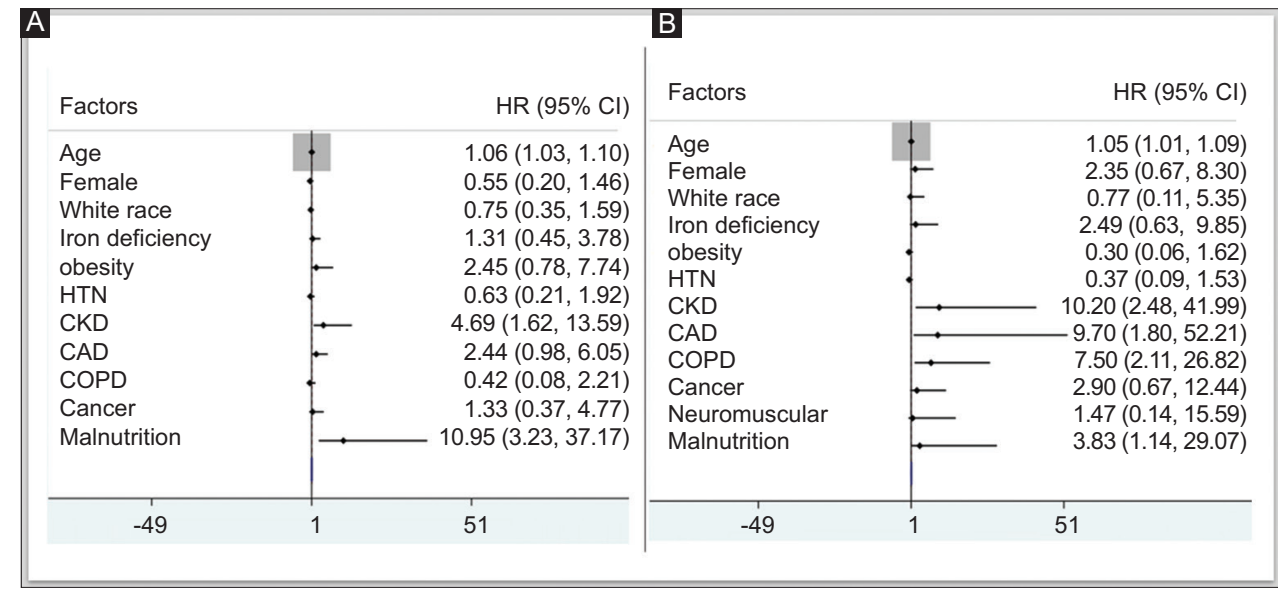

Figure 3 (A) Forest plot of predictors of mortality in diabetics with gastroparesis. (B) Forest plot showing the predictors of mortality in nondiabetic gastroparesis

HTN, hypertension; CAD, coronary artery disease; CKD, chronic kidney disease; COPD, chronic obstructive pulmonary disease

by $0.55 \pm 3.9 \mathrm{~kg} / \mathrm{m}^{2}$ in 6 months from baseline, there was no correlation of this BMI change with the presence or absence of DM ( $\mathrm{r}=0.2, \mathrm{P}=0.59)$. The diabetics had a greater drop in serum albumin after 6 months from diagnosis compared to nondiabetics $(0.13 \pm 0.5$ vs. $-0.03 \pm 0.5 \mathrm{mg} / \mathrm{dL}$, $\mathrm{r}=0.15, \mathrm{P}=0.03)$. The vitamin and mineral deficiencies were similar in both diabetics and nondiabetic gastroparesis. Vitamin D deficiency was seen in $49.7 \%$ of the population. The mean vitamin D level was $22.6 \pm 10.7 \mathrm{ng} / \mathrm{mL}$. Vitamin B12 deficiency was observed in 17.5\% (mean $456.6 \pm 214.7 \mathrm{pg} / \mathrm{mL}$ ), whereas iron deficiency was observed in $50.3 \%$ of the population. The mean albumin level was $3.6 \pm 0.7 \mathrm{~g} / \mathrm{dL}$. The nutritional service evaluated $19.4 \%$ of the population (Table 1). Patients who had undergone nutritional evaluation had higher mortality (diabetics HR 2.37, 95\%CI 0.88-6.36; $\mathrm{P}=0.08$ vs. nondiabetics HR 4.68, 95\%CI 1.44-15.18; $\mathrm{P}=0.01)$.

\section{Discussion}

To date, this is the largest study to examine the outcomes of patients with nondiabetic and diabetic gastroparesis confirmed by a gastric emptying study. Our study found that the mortality rate in gastroparesis patients over 3.7-year period was $14.4 \%$. We observed that malnutrition and common comorbid conditions, such as CAD, CKD, and COPD, played an important role in defining the prognosis of these patients. DM itself was not associated with increased risk of mortality in these patients. Advanced age, a history of CKD, CAD, COPD and malnutrition were associated with greater mortality in both diabetics and nondiabetics. We also found that both the groups had a high incidence of micronutrient deficiencies, including iron, and vitamins B12 and D. Despite the high nutritional deficiencies, only $19.4 \%$ patient had a documented nutritional evaluation. Our study is novel, as it determined the 
predictors of a poor outcome in gastroparesis patient, which have not previously been discussed in detail in the literature.

A strength of this study is the use of a gastric emptying study to define gastroparesis, rather than using gastrointestinal symptoms that are vague and subjective. Prior populationbased studies are limited because the diagnosis of gastroparesis was based on the symptoms rather than on the purely objective evidence of a nuclear gastric emptying study, as in our study $[3,18,19]$. Rapid gastric emptying and functional dyspepsia can also present with symptoms similar to gastroparesis; thus, reported delayed gastric transit is important for the diagnosis of gastroparesis $[1,20]$. Another strength of our study is the inclusion of both nondiabetic and diabetic gastroparesis. Previously reported studies were limited to patients with diabetic gastroparesis [3,21]. One popular study based on the Rochester Epidemiology Project (REP) [8] showed that gastroparesis patients had higher than expected mortality (33\% in 5 years). In our cohort, the average age of death for gastroparesis patients was $61.4 \pm 14.9$ years, much lower than the overall life expectancy in the USA [22]. The REP study also demonstrated that age, male sex, and non-idiopathic gastroparesis (including $\mathrm{DM}$ ) were associated with poor survival. We observed that the survival of nondiabetic gastroparesis was better than the survival of diabetic gastroparesis. This could be explained by the higher comorbidity burden of diabetic patients.

A 1998 study of 146 patients diagnosed with gastroparesis based on a mix of gastric emptying study and symptoms showed greater morbidity among these patients. Over 6 years follow up 7\% patients died [9]. A smaller study of 86 Australian adults showed that DM itself was not associated with increased mortality, but rather the duration of DM: the mortality rate was $33.7 \%$ over 25 years $[10,23]$. However, this study could have suffered from beta error due to its small sample size, and may have missed the impact of diabetic gastroparesis on mortality. Our study further strengthens the previously expected notion that diabetic gastroparesis patients tend to have a higher mortality.

Studies based on the National Health and Nutrition Examination Survey have shown that the prevalence of vitamin D deficiency in the general population is $5.4-7.5 \%$, while approximately $3.2 \%$ of the population have low vitamin B12 and iron deficiency anemia is 2-3\% (although females and toddlers may have a higher prevalence) [24-26]. Our study showed that patients with gastroparesis have a significantly higher number of vitamin D (49.7\%), vitamin B12 (17.5\%), and iron (50.3\%) deficiencies compared to the general population. The mean hemoglobin level was lower in diabetic gastroparesis $(\mathrm{P}=0.03)$, whereas vitamin $\mathrm{D}$ and $\mathrm{B} 12$ levels were not statistically different in the 2 groups. The prevalence of proton-pump inhibitor use was higher in this cohort, which could have contributed to the iron and vitamin deficiency [27]. A study by the National Institute of Diabetes and Digestive and Kidney Diseases (NIDDK) Gastroparesis Registry [5] showed a greater prevalence of micronutrient deficiency in gastroparesis, including iron, calcium, potassium, and vitamins C, D, E and K. Only 32\% of patients in NIDDK gastroparesis registry (January 2007 to March 2010) received nutritional counseling [5]. Our study showed an even lower utilization of nutritional consultation (19.4\%), which could explain the higher prevalence of nutritional deficiencies. Interestingly, the patients seen by nutritional service had higher mortality. It is possible that nutritional counselling was considered in patients who were sicker and had more comorbid conditions.

Other strengths of our study include the diversity of the patient population, the large sample size, granularity in obtaining patient characteristics, and complete follow up for the duration of the study period. The gastroparesis diagnosis was based on the Tougas protocol, unlike previous studies that used the older criteria of $50 \%$ or less emptying of stomach at $60 \mathrm{~min}$, which is a less specific protocol [28]. To better understand the outcomes, we avoided overmatching subjects diagnosed with gastroparesis but had a normal gastric emptying study.

Our study also had several limitations, including the retrospective study design and single-center setting. We tried to avoid the errors by using 2 reviewers independently collecting information from the medical records. ICD 9 and ICD 10 codes were used to identify the patients. It is possible that a few patients might have been misclassified, though careful chart auditing was performed to limit the misdiagnosis. Nondiabetic gastroparesis was not further classified into idiopathic and other causes. The DM cases were not categorized into type 1 and 2 , and as a result the outcomes were not studied in further subgroups.

In summary, gastroparesis with or without DM has a poor prognosis. The traditional risk factors of increased mortality in the general population, including older age, CAD, CKD, COPD and malnutrition, remained the major predictors of mortality. Clinical malnutrition, vitamin D, B12 and iron deficiencies were commonly observed in both diabetic and nondiabetic gastroparesis. Nutritional counseling was underutilized. More epidemiological studies in the community are indicated to better understand the course of the disease.

\section{Summary Box}

\section{What is already known:}

- Gastroparesis is associated with high morbidity and mortality

- Nutrition evaluation is underutilized in the gastroparesis population

- Micronutrient deficiencies are commonly seen in gastroparesis patients

\section{What the new findings are:}

- Advanced age, malnutrition, chronic kidney disease, chronic obstructive pulmonary disease, and coronary artery disease were associated with higher mortality in gastroparesis

- Patients with diabetes mellitus had more severe gastroparesis compared to nondiabetics

- Gastroparesis patients with diabetes mellitus died earlier during the disease course 


\section{References}

1. Camilleri M, Parkman HP, Shafi MA, Abell TL, Gerson L; American College of Gastroenterology. Clinical guideline: management of gastroparesis. Am J Gastroenterol 2013;108:18-37.

2. Rey E, Choung RS, Schleck CD, Zinsmeister AR, Talley NJ, Locke GR $3^{\text {rd }}$. Prevalence of hidden gastroparesis in the community: the gastroparesis "iceberg". J Neurogastroenterol Motil 2012;18:34-42.

3. Choung RS, Locke GR $3^{\text {rd }}$, Schleck CD, Zinsmeister AR, Melton LJ $3^{\text {rd }}$, Talley NJ. Risk of gastroparesis in subjects with type 1 and 2 diabetes in the general population. Am J Gastroenterol 2012;107:82-88.

4. Abell TL, Bernstein RK, Cutts T, et al. Treatment of gastroparesis: a multidisciplinary clinical review. Neurogastroenterol Motil 2006; 18:263-283.

5. Parkman HP, Yates KP, Hasler WL, et al; NIDDK Gastroparesis Clinical Research Consortium. Dietary intake and nutritional deficiencies in patients with diabetic or idiopathic gastroparesis. Gastroenterology 2011;141:486-498, 498.e1-e7.

6. Wadhwa V, Mehta D, Jobanputra Y, Lopez R, Thota PN, Sanaka MR. Healthcare utilization and costs associated with gastroparesis. World J Gastroenterol 2017;23:4428-4436.

7. Wang YR, Fisher RS, Parkman HP. Gastroparesis-related hospitalizations in the United States: trends, characteristics, and outcomes, 1995-2004. Am J Gastroenterol 2008;103:313-322.

8. Jung HK, Choung RS, Locke GR $3^{\text {rd }}$, et al. The incidence, prevalence, and outcomes of patients with gastroparesis in Olmsted County, Minnesota, from 1996 to 2006. Gastroenterology 2009;136:1225-1233.

9. Soykan I, Sivri B, Sarosiek I, Kiernan B, McCallum RW. Demography, clinical characteristics, psychological and abuse profiles, treatment, and long-term follow-up of patients with gastroparesis. Dig Dis Sci 1998;43:2398-2404.

10. Kong MF, Horowitz M, Jones KL, Wishart JM, Harding PE. Natural history of diabetic gastroparesis. Diabetes Care 1999;22:503-507.

11. Ogorek CP, Davidson L, Fisher RS, Krevs.ky B. Idiopathic gastroparesis is associated with a multiplicity of severe dietary deficiencies. Am J Gastroenterol 1991;86:423-428.

12. Camilleri M. Clinical practice. Diabetic gastroparesis. N Engl J Med 2007;356:820-829.

13. Johnson-Wimbley TD, Graham DY. Diagnosis and management of iron deficiency anemia in the $21^{\text {st }}$ century. Therap Adv Gastroenterol 2011;4:177-184.

14. Sacks DB, Arnold M, Bakris GL, et al; Evidence-Based Laboratory Medicine Committee of the American Association for Clinical Chemistry. Guidelines and recommendations for laboratory analysis in the diagnosis and management of diabetes mellitus. Diabetes Care 2011;34:e61-e99.

15. Levey AS, Stevens LA, Schmid CH, et al; CKD-EPI (Chronic Kidney
Disease Epidemiology Collaboration). A new equation to estimate glomerular filtration rate. Ann Intern Med 2009;150:604-612.

16. Cederholm T, Bosaeus I, Barazzoni R, et al. Diagnostic criteria for malnutrition - An ESPEN Consensus Statement. Clin Nutr 2015;34:335-340.

17. White JV, Guenter P, Jensen G, Malone A, Schofield M; A.S.P.E.N. Board of Directors. Consensus statement: Academy of Nutrition and Dietetics and American Society for Parenteral and Enteral Nutrition: characteristics recommended for the identification and documentation of adult malnutrition (undernutrition). JPEN J Parenter Enteral Nutr 2012;36:275-283.

18. Talley NJ, Howell S, Jones MP, Horowitz M. Predictors of turnover of lower gastrointestinal symptoms in diabetes mellitus. Am J Gastroenterol 2002;97:3087-3094.

19. Bytzer P, Talley NJ, Leemon M, Young LJ, Jones MP, Horowitz M. Prevalence of gastrointestinal symptoms associated with diabetes mellitus: a population-based survey of 15,000 adults. Arch Intern Med 2001;161:1989-1996.

20. Bredenoord AJ, Chial HJ, Camilleri M, Mullan BP, Murray JA. Gastric accommodation and emptying in evaluation of patients with upper gastrointestinal symptoms. Clin Gastroenterol Hepatol 2003;1:264-272.

21. Maleki D, Locke GR $3^{\text {rd }}$, Camilleri M, et al. Gastrointestinal tract symptoms among persons with diabetes mellitus in the community. Arch Intern Med 2000;160:2808-2816.

22. Murphy S, Xu J, Kochanek K, Arias E. Mortality in the United States, 2017. CDC NCHS Data Brief 2018;(328):1-8.

23. Chang J, Rayner CK, Jones KL, Horowitz M. Prognosis of diabetic gastroparesis-a 25-year evaluation. Diabet Med 2013;30:e185-e188.

24. Schleicher RL, Sternberg MR, Lacher DA, et al. The vitamin D status of the US population from 1988 to 2010 using standardized serum concentrations of 25-hydroxyvitamin D shows recent modest increases. Am J Clin Nutr 2016;104:454-461.

25. Evatt ML, Terry PD, Ziegler TR, Oakley GP. Association between vitamin B12-containing supplement consumption and prevalence of biochemically defined B12 deficiency in adults in NHANES III (third national health and nutrition examination survey). Public Health Nutr 2010;13:25-31.

26. Centers for Disease Control and Prevention (CDC). Iron deficiency-United States, 1999-2000. MMWR Morb Mortal Wkly Rep 2002;51:897-899.

27. Heidelbaugh JJ. Proton pump inhibitors and risk of vitamin and mineral deficiency: evidence and clinical implications. Ther $A d v$ Drug Saf 2013;4:125-133.

28. Tougas G, Eaker EY, Abell TL, et al. Assessment of gastric emptying using a low fat meal: establishment of international control values. Am J Gastroenterol 2000;95:1456-1462. 


\section{Supplementary material}

Supplementary Table 1 Causes of death in diabetics and nondiabetics with gastroparesis (percentage of total deaths in the groups)

\begin{tabular}{lcc} 
Causes of death & $\begin{array}{c}\text { Diabetes } \\
\text { mellitus (\%) }\end{array}$ & $\begin{array}{c}\text { Nondiabetic } \\
(\%)\end{array}$ \\
\hline Heart disease & 33.3 & 26.3 \\
Chronic kidney disease & 18.5 & 5.3 \\
\hline Cancer & 18.5 & 0 \\
\hline Infections & 14.8 & 26.3 \\
\hline Cerebrovascular disease & 3.7 & 10.5 \\
\hline Chronic lung disease & 0 & 15.8 \\
\hline Chronic liver disease & 3.7 & 0 \\
\hline Malnutrition & 7.4 & 0 \\
\hline Alcohol abuse & 0 & 5.3 \\
\hline Accidents & 0 & 5.3 \\
\hline
\end{tabular}

